\title{
Myosin ATPase and Acto-Heavy Meromyosin ATPase in Normal and in Pale, Soft and Exudative (PSE) Porcine Muscle
}

\author{
Sam Kyung SunG, ${ }^{*}$ Tatsumi ITO** and Kenjiro IzUmI*** \\ Laboratory of Chemistry and Technology of Animal Products, Faculty of Agriculture, \\ Kyushu University, Fukuoka 812, Japan
}

Received October 20, 1980

\begin{abstract}
An investigation was conducted on myosin and actin-activated heavy meromyosin (HMM) ATPase activities in normal porcine muscle stored for varying periods of time after death. Studies were also made on temperature dependent myosin ATPase, initial burst of ATPase and actinactivated HMM ATPase in normal and in pale, soft and exudative (PSE) porcine muscle. The maximum velocity of acto-HMM ATPase of normal muscle decreased considerably with postmortem time, while the apparent dissociation constant decreased slightly. The maximum velocity of acto-HMM ATPase of postmortem normal muscle was approximately two-times larger than that of the corresponding PSE muscle. However, almost no difference was found in the apparent dissociation constant. The size of the initial burst of phosphate-liberation of myosin prepared from normal muscle was approximately $1.2 \mathrm{~mol} / \mathrm{mol}$ of myosin and from PSE muscle 0 . It is assumed that the lack of contractility of PSE muscle was brought about by two basic myosin malfunctions: one, the irreversible binding of myosin to actin filament and the other, the functional damage of myosin ATPase, responsible for the formation of phosphorylated complex, even when dissociable.
\end{abstract}

Pale, soft and exudative (PSE) porcine muscle known as a low quality pork occurs in some types of pigs after slaughter. ${ }^{11}$ The occurrence of PSE muscle is also dependent upon the physiological conditions of muscle and the condition for producing PSE muscle is developed during early rigor process of muscle. ${ }^{2,3)}$ It has been established that high temperature and low $\mathrm{pH}$ occurring in an early postmortem muscle cause the denaturation of myofibrillar proteins. ${ }^{4} 9$ ) Fuchs $^{10)}$ showed that with the increase in temperature the inhibitory action of troponin-tropomyosin system in actomyosin was progressively reduced. Park et al. ${ }^{11)}$ showed that calcium sensitivity of myosin B prepared from PSE muscle was partially lost. In a previous paper, we have reported that normal myofibril prepared from $24 \mathrm{hr}$ postmortem muscle is able to

* Present address: Yeung Nam University, Daegu, Korea.

** To whom correspondence should be addressed.

*** Present address: Muscle Biology Laboratory, University of Wisconsin, Madison, Wisconsin. contract upon addition of $\mathrm{Mg}^{2+}$-ATP, while PSE myofibril contract in part or cannot contract, even though PSE myofibril retains partially its $\mathrm{Mg}^{2+}$-ATPase activity. ${ }^{12)}$ This result suggests that contraction is apparently uncoupled with $\mathrm{Mg}^{2+}$-ATPase in PSE muscle.

In the present study, we have investigated myosin and actin-activated heavy meromyosin (HMM) ATPase activities of normal porcine muscle stored for varying periods after death. We have also investigated temperature dependent myosin ATPase, initial burst of the ATPase and acto-HMM ATPase of normal and PSE muscle, and discussed the interrelationship between the contractility of muscle and the size of initial burst of phosphateliberation (Pi-liberation). A part of this study has been published elsewhere in a preliminary form. ${ }^{13)}$

\section{MATERIALS AND METHODS}

Materials. Selection of normal and PSE porcine muscle was done by measuring $\mathrm{pH}$ and testing contractility of 
myofibrils of $24 \mathrm{hr}$ postmortem longissimus thoracis muscle as described in a previous paper ${ }^{12}$ ): the muscles having high $\mathrm{pH}$ values ( $\mathrm{pH} 5.44,5.48,5.52$ and 5.58) and full contractility were classified as normal, and the muscles having low $\mathrm{pH}$ values ( $\mathrm{pH} 5.28,5.24$ and 5.18) and no contractility and those having intermediate $\mathrm{pH}(\mathrm{pH} 5.33$ and 5.36) and contractility $(60 \%$ contractility for both muscles) were also classified as PSE and slightly PSE muscle, respectively.

Myosin was prepared from porcine muscle immediately after death and the muscles stored for 24 and $168 \mathrm{hr}$ at $0 \sim 5^{\circ} \mathrm{C}$ by the method of Quass and Briskey ${ }^{143}$ with slight modifications: ultracentrifugation was done at $100,000 \times g$ for $2 \mathrm{hr}$ instead of centrifugation at $30,000 \times \mathrm{g}$ for $30 \mathrm{~min}$ in the original method. A modified Guba-Straub solution $(0.3 \mathrm{M} \mathrm{KCl}, 0.15 \mathrm{M} \mathrm{K}$-phosphate, I mM ethyleneglycol-bis(2-aminoethylether)- $N, N, N^{\prime}, N^{\prime}$-tetraacetic acid (EGTA), $5 \mathrm{~mm}$ ATP, $5 \mathrm{~mm} \mathrm{MgCl}_{2}$, pH 6.5) was used for the extraction of myosin from aged muscles. Myosin was stored in $50 \%$ glycerol $(\mathrm{v} / \mathrm{v})$ at $-20^{\circ} \mathrm{C}$ until use.

HMM was obtained by the method of Lowey and Cohen $^{15)}$ with slight modifications: trypsin digestion was done for $4 \mathrm{~min}$ at $25^{\circ} \mathrm{C}$, and purification of HMM was made by ammonium sulfate fractionation between $42 \sim 58 \%$ saturation, and then dialyzed against $40 \mathrm{~mm}$ $\mathrm{KCl}, 10 \mathrm{~mm}$ Tris-maleate $(\mathrm{pH} 7.0), 1 \mathrm{~mm}$ dithiothreitol (DTT) prior to use in the assay. Actin was prepared according to the method of Spudich and Watt, ${ }^{16)}$ except that the time of polymerization was prolonged overnight instead of $2 \mathrm{hr}$ in the original method. This prolongation of the time for polymerization brought about no significant change of the SDS polyacrylamide gel electrophoretogram of actin (data not shown).

All operations were conducted at $5^{\circ} \mathrm{C}$ or below except where otherwise noted, and all determinations were performed within 3 days for HMM and 5 days for actin after preparation.

ATPase activity. The enzymatic assay of myosin ATPase was performed in water-bath at $25^{\circ} \mathrm{C}$ for $1 \sim 8 \mathrm{~min}$ with 1 min intervals. The total volume of reaction mixture was $2.0 \mathrm{ml}$. The reaction was stopped by adding equal volume of cold $10 \%$ trichloroacetic acid (TCA), followed by centrifugal removal of the protein precipitate. The inorganic phosphate liberated was determined by the method of Fiske and Subbarow, ${ }^{17}$ and the results were expressed as specific activity in terms of $\mu \mathrm{mol}$ of inorganic phosphate liberated $/ \mathrm{min} / \mathrm{mg}$ protein.

The reaction of actin-activated HMM ATPase activity was carried out in the same way as described above, except that the reaction was initiated by the addition of HMM. The measured ATPase activity was corrected by substracting the ATPase activity of added HMM in the absence of actin from the activity of acto-HMM ATPase. The apparent dissociation constant was calculated from the abscissa, assuming a binding ratio of $4.2 \times 10^{-4} \mathrm{~g}$ of actin. $^{18,19)}$
The initial burst of myosin ATPase was examined in a medium containing high concentration of salt. The reaction was stopped by adding 10\% TCA (final concentration $5 \%$ ) at appropriate times (usually $20,40,60,80$, 100,120 and $150 \mathrm{sec}$ ) after the start of the reaction. The amount of liberated inorganic phosphate was determined by the method of Martin and Doty ${ }^{20)}$ with slight modifications. $^{211}$

Contractility and $p H$ measurement. Contractility of myofibrils and $\mathrm{pH}$ of muscles were tested according to the methods described in a previous paper. ${ }^{12)}$

Protein concentration. Protein concentration was measured by the biuret reaction. ${ }^{22)}$

\section{RESULTS}

\section{Postmortem change of acto-HMM ATPase}

Figure 1 shows the double-reciprocal plots of the actin-activated HMM ATPase of normal porcine muscle stored for varying periods after death. In this figure, the intercept on the ordinate gives the maximum velocity $\left(V_{\max }\right)$ of

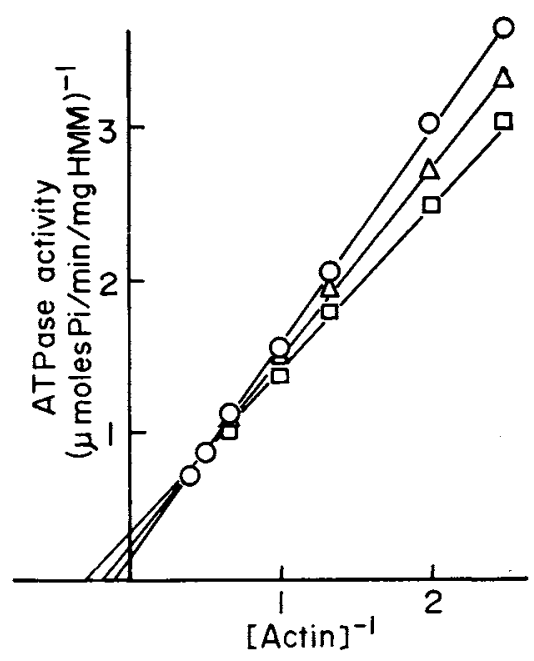

FIG. 1. Double-reciprocal Plots of Acto-HMM ATPase of at Death and Postomortem Muscle.

Acto-HMM ATPase activity was measured at $25^{\circ} \mathrm{C}$ in a medium containing $40 \mathrm{mM} \mathrm{KCl}, 1 \mathrm{~mm} \mathrm{MgCl}, 2 \mathrm{~mm} \mathrm{ATP}$, $10 \mathrm{~mm}$ Tris-maleate $(\mathrm{pH} 7.0)$ and varying concentrations of actin $(0.4 \sim 2.5 \mathrm{mg} / \mathrm{ml})$ with a constant concentration of $\mathrm{HMM}, 0.2 \mathrm{mg} / \mathrm{ml}$.

$O$, at death muscle; $\triangle, 24 \mathrm{hr}$ postmortem muscle; $\square$, $168 \mathrm{hr}$ postmortem muscle. Normal porcine muscle $\left(\mathrm{pH}_{24}=5.48\right.$, contractility $\left.100 \%\right)$ was used in this experiment. 
the acto-HMM ATPase; analogously the intercept on the abscissa yields the apparent dissociation constant $\left(K_{\mathrm{app}}\right)$ of the complex. ${ }^{23)}$ As shown in this figure, the $V_{\max }$ considerably decreased with postmortem time, while the $K_{\text {app }}$ decreased a little: the $V_{\max }$ of acto-HMM ATPase of 0,24 and $168 \mathrm{hr}$ postmortem porcine muscle was $5.71,4.18$ and $2.98 \mu \mathrm{mol}$ $\mathrm{Pi} / \mathrm{min} / \mathrm{mg}$ of $\mathrm{HMM}$ and the $K_{\mathrm{app}}$ was $1.91 \times 10^{-4}, 1.23 \times 10^{-4}$, and $7.44 \times 10^{-5} \mathrm{M}$, respectively. These results are consistent with the findings on the acto-HMM ATPase of rabbit postmortem skeletal muscle. ${ }^{24,25)}$

\section{Acto-HMM ATPase of $24 \mathrm{hr}$ postmortem por- cine muscle}

The $V_{\max }$ and $K_{\text {app }}$ of actin-activated HMM ATPase of normal and PSE porcine muscles were also obtained from the double reciprocal plots of the ATPase (Table I). As shown in Table I, the $V_{\max }$ decreased with decreasing $\mathrm{pH}$ and with decreasing contractility of the muscles. The $V_{\max }$ of actoHMM ATPase of normal muscle was approximately two times larger than that of PSE muscle. This indicates that actin activation of HMM ATPase of PSE muscle at infinite actin concentration was less than that of normal muscle. However, almost no difference was observed in the $K_{\mathrm{app}}$.

\section{Arrhenius plots of myosin ATPase}

Figure 2 shows the Arrhenius plots of myosin ATPase activity of normal and PSE porcine muscles. Muscles prepared from $24 \mathrm{hr}$ postmortem porcine muscles were used in this experiment. The apparent activation energies, $E_{\mathrm{a}}$, of myosins prepared from normal, slightly PSE and PSE muscles were 8.64, 6.11 and 5.86 $\mathrm{kcal} / \mathrm{mol}$, respectively. Thus the activation free energy of myosin prepared from normal muscle is slightly higher than that of PSE muscle. This suggests that some alterations of enzymatic function of myosin might occur in PSE muscle in which muscle proteins are inactivated during the development of PSE conditions.

\section{TABLE I. ACTIN-ACTIYATED HMM ATPASE of NoRmal aND PSE MưCle}

The $V_{\max }$ and $K_{\text {app }}$ of normal and slightly PSE muscle were the averages of two determinations on two different

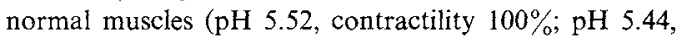
contractility $100 \%$ ) and two different slightly PSE muscles (pH 5.33, contractility 60\%; pH 5.36, contractility $60 \%$ ), respectively. The values of PSE muscle were the averages of two determinations on one PSE muscle ( $\mathrm{pH} 5.28$, contractility $0 \%$ ).

\begin{tabular}{lcc} 
Porcine muscle & $\begin{array}{c}V_{\max } \\
(\mu \mathrm{mol} \mathrm{Pi/min} / \mathrm{mg} \\
\mathrm{HMM})\end{array}$ & $\begin{array}{c}K_{\text {app }} \\
(\mathrm{M})\end{array}$ \\
\hline Normal & 3.846 & $11.45 \times 10^{-5}$ \\
Slightly PSE & 3.704 & $11.45 \times 10^{-5}$ \\
PSE & 2.041 & $11.18 \times 10^{-5}$ \\
\hline
\end{tabular}

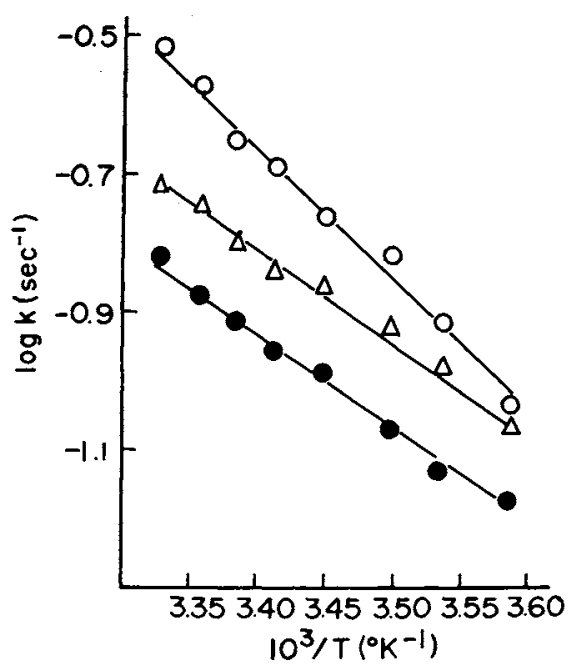

FIG. 2. Arrhenius Plots of Normal, Slightly PSE and PSE Muscle Myosin ATPase.

Myosin ATPase measurements were carried out at varying temperatures in a reaction mixture containing $0.5 \mathrm{M} \mathrm{KCl}, 4 \mathrm{mM} \mathrm{CaCl}, 1 \mathrm{~mm} \mathrm{ATP}$ and $10 \mathrm{~mm}$ Trismaleate, $\mathrm{pH}$ 7.0. The concentration of myosin was $0.2 \mathrm{mg} / \mathrm{ml}$.

$\mathrm{O}$, myosin prepared from normal muscle $(\mathrm{pH} 5.44$, contractility $10 \%) ; \Delta$, myosin prepared from slightly

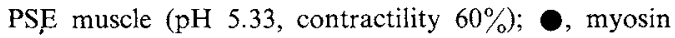
prepared from PSE muscle ( $\mathrm{pH} 5.28$, contractility $0 \%$ ).

\section{Initial burst of normal and PSE myosins}

The determination of the initial burst of Piliberation of myosin was conducted on two normal and two PSE myosins. In each case 
Regeneration of NADPH by Frozen-thawed Cells of a Blue-green Alga, Synechococcus sp.

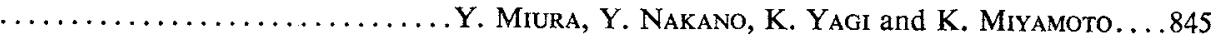

D-Glucose Dehydrogenase of Gluconobacter suboxydans: Solubilization, Purification and Charac-

terization.............. Ameyama, E. Shinagawa, K. Matsushita and $O$. Adachi . . 851

Methane Fermentation of Coffee Grounds and Some Factors to Improve the Fermentation

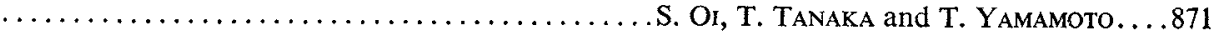

Antifungal Activity of Components of Essential Oils ... N. Kurita, M. MrYaJI, R. Kurane and Y. TaKahara... 945

L-Arginine Production by Arginine Analog-resistant Mutants of Microorganisms

H. Yoshida, K. Araki and K. Nakayama....959

\section{Pesticide Chemistry}

Synthesis of Some $O, O$-Dialkyl $N$-[4-( $N$-heteroarylsulfamoyl)phenyl]phosphoramidothioates as

Potential Fungicides.................................... Giri and Y. Singh 839

\section{Notes}

Penicillin-Binding Proteins in Selenomonas ruminantium............... Kamı and Y. TerawaKı... 993

Effects of Trialkyltin Chlorides on Escherichia coli Spheroplasts....................... YAMADA... 997

Adsorption Specificity of Immobilized Tannin for Proteins and Other Organic Compounds

.T. Watanabe, T. Mori, T. Tosa and I. Chibata....1001

Effect of Temperature on Growth of Bacillus sp. T-4, a Thermophilic Acidophilic Bacterium

.......................................... UchINO and T. KaTANO...1005

Variation in Casein from Individual Human Milk Samples. . . N. Azuma, H. KobaYashi and K. Yamauchi . . . 1007

Stopped-Flow Measurement of Reaction Rate of Dihydroxyfumaric Acid with 2,6-Dichlorophenolin-

dophenol........................... Obata, M. Tatsuno and T. Tokuyama....1011

Purification of Oat Debranching Enzyme and Occurrence of Inactive Debranching Enzyme in

Cereals................................................ Yamada...1013

Enrichment of $n$-Alkane Assimilation-Deficient Mutants of Candida Yeast by Synergistic Effect of

Nystatin and Pyrrolnitrin................ Yano, M. Kawamura and M. Takagi....1017

In Vitro Stimulation by Parathion of Porcine Pancreatic Carboxylesterase Activity toward Triacetin

...T. Komura and H. Nagayama....1019

Determination of L-Cysteine with L-Methionine $\gamma$-Lyase...H. TANAKA, H. IMAHARA, N. Esakr and K. SOdA... 1021

Isolation and Biological Activity of a Peptidal Antibiotic P168

.A. Isogai, A. Suzuki, S. Higashikawa, S. Kuyama and S. Tamura....1023

\section{Rapid Papers}

Application of Plasmid to ATP Production by E. coli........... Shimosaka, Y. FukUdA and A. Kimura....1025

1'-(6-Hydroxyoctanoyl) nornicotine and 1'-(7-Hydroxyoctanoyl)nornicotine, Two New Alkaloids from Japanese Domestic Tobacco

M. Miyano, N. Yasumatsu, H. Matsushita and K. Nishida....1029

\section{Short Communications}

Mode of Action of a New Aspergillus oryzae Carboxypeptidase O-1 .... M. TAKEUCHI and E. ICHISHIMA....1033 Mutagenicity of the Gaseous Phase of Protein Pyrolysis Product in Salmonella

A. Kushi, H. Tsuda, D. Yosmida and F. Gotō....1037

New Aspartate Aminotransferase Inhibitor (Gostatin) Produced by Streptomyces sumanensis Nov.

sp., NK-23............... Murao, T. Nishino, N. Katayama and H. Nagano....1039

Isolation of Tremerogen $a-13$, a Peptidal Sex Hormone of Tremella mesenterica

........................ Yoshida, Y. Sakagami, A. Isogai and A. Suzuki.... 1043

Structure of Tremerogen $a-13$, a Peptidal Sex Hormone of Tremella mesenterica

.......................... Y. SAKagami, M. Yoshida, A. Isogai and A. Suzuki.....1045

Synthesis and Structure-Activity Relations of Tremerogen $a-13$, a Peptidal Sex Hormone of Tremella mesenterica ...................................... KITAdA,

M. Fuino, Y. SaKagami, M. Yoshida, A. Isogai and A. SuzuKı....1049

\section{Abstracts}

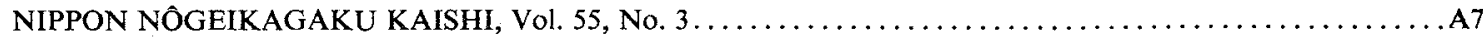


contractility of PSE muscle is brought about by two basic malfunction of myosin, namely, one is the irreversible binding to actin filament ${ }^{33)}$ and the other is the functional damage of the ATPase active site responsible for the formation of the phosphorylated complex, even if it is dissociable.

Acknowledgment. We are grateful to Dr. T. Fukazawa, Kyushu University, for his helpful discussion and encouragement during the course of this work. We thank Dr. M. L. Greaser, University of Wisconsin, for reading the manuscript. This work was supported by a grant from the Ministry of Education, Science and Culture of Japan. We also thank Dr. Y. Ikeuchi for discussion.

\section{REFERENCES}

1) D. G. Topel, E. J. Bicknell, K. S. Preston, L. L. Christian and C. Y. Matsushima, Mod. Vet. Prac., 49, 40 (1968)

2) R. G. Cassens, D. N. Marple and G. Eikelenboom, Adv. Food Res., 21, 71 (1975).

3) T. Ito, Niku no Kagaku, 17, 30 (1976), (in Japanese).

4) R. N. Sayer and E. J. Briskey, J. Food Sci., 28, 675 (1963).

5) E. J. Briskey and R. N. Sayre, Proc. Sci. Exptl. Biol. Med., 115, 873 (1964).

6) D. E. Galloway and D. E. Goll, J. Anim. Sci, 26, 1302 (1967).

7) I. F. Penny, J. Food Technol., 4, 269 (1969).

8) M. L. Greaser, R. G. Cassens, E. J. Briskey and W. G. Hoekstra, J. Food Sci, 34, 120 (1969).

9) T. Yasui, T. Sumita and S. Tsunogae, J. Agric. Food Chem., 23, 1163 (1975)

10) F. Fuchs, Anesthesiol., 42, 583 (1975).

11) H. K. Park, T. Ito and T. Fukazawa, Jpn. J. Zootech. Sci., 48, 654 (1977).

12) S. K. Sung, T. Ito and T. Fukazawa, J. Food Sci, 41, 102 (1976).

13) S. K. Sung, T. Ito and T. Fukazawa, Thesis
Collection, Yeung Nam Univ., Daegu, Korea, 11, 175 (1977).

14) D. W. Quass and E. J. Briskey, J. Food Sci, 33, 180 (1968).

15) S. Lowey and C. Cohen, J. Mol. Biol., 4, 293 (1962).

16) J. A. Spudich and S. Watt, J. Biol. Chem., 245, 4866 (1971).

17) C. H. Fiske and Y. Subbarow, J. Biol. Chem., 66, 375 (1925).

18) M. Elzinga, J. H. Collins, W. M. Kuehl and R. S. Adelstein, Proc. Natl. Acad. Sci. U.S.A., 70, 2687 (1973).

19) A. A. Rizzino, W. W. Barouch, E. Eisenberg and C. Moos, Biochemistry, 9, 2402 (1970).

20) J. B. Martin and D. M. Doty, Anal. Chem., 21, 965 (1949).

21) O. Lindberg and L. Ernster, "Methods of Biochemical Analysis," Vol. III, 1956, p. 1.

22) A. G. Gornall, C. T. Bardawill and M. M. David, J. Biol. Chem., 177, 751 (1949).

23) E. Eisenberg and C. Moos, Biochemistry, 7, 1486 (1968).

24) T. Ito, S. K. Sung and T. Fukazawa, J. Agric. Food Chem., 26, 324 (1978).

25) Y. Ikeuchi, T. Ito and T. Fukazawa, J. Agric. Food Chem., 28, 1197 (1980).

26) M. Yazawa, F. Morita and K. Yagi, J. Biochem., 74, 1107 (1973).

27) T. Hozumi and K. Tawada, Biochim. Biophys. Acta, 376, 1 (1975).

28) K. Tawada and A. Yoshida, J. Biochem., 78, 273 (1975).

29) A. Inoue, K. Shibata, K. Sekiya and Y. Tonomura, $J$. Biochem., 71, 115 (1972).

30) J. R. Bendall, "The Structure and Function of Muscle," 2nd Ed., Vol. 1, ed. by G. H. Bourne, Academic Press, Inc., New York, 1973, p. 243.

31) D. E. Goll, Proceedings of the Meat Industry Research Conference, Chicago, 1974, p. 75.

32) E. Taylor, Y. Tonomura and A. Inoue, Trends in Biochem. Sci., 2, N32 (1977).

33) K. Izumi, T. Ito and T. Fukazawa, J. Food Sci., 43, $1338(1978)$. 